\title{
A review of inter-firm relationship quality in supply chains
}

\author{
Chen Qian \\ Faculty of Business Economics, Chair of Supply Chain Management, \\ University of Kassel, Kassel, Germany \\ Stefan Seuring \\ Faculty of Business Economics, Chair of Supply Chain Management, \\ University of Kassel, Kassel, Germany \\ Ralf Wagner \\ Faculty of Business Economics, Chair of Sustainable Marketing, \\ University of Kassel, Kassel, Germany
}

\begin{abstract}
Purpose - This paper aims to conduct a review of the recent literature on inter-firm relationship quality (RQ) in supply chain (SC) settings.

Design/methodology/approach - 100 English-language scientific publications on interfirm RQ, published from 2006 to 2015 were selected and analyzed by using a content analysis approach.

Findings - The results of the frequency analysis map the antecedents, dimensions and consequences - particularly the performance and behavioral intentions of collaborating partners - of buyer-seller RQ presented in the current literature. The contingency analysis offers insights into the use of relevant constructs of inter-firm RQ in SCs in the individual papers. A range of research gaps is uncovered.
\end{abstract}

Research limitations/implications - The category building for the content analysis was based on a RQ framework that focuses on the mediator structure and neglects the effects of moderators.

Practical implications - The developed framework of inter-firm RQ in SCs provides managers with a guide to the relevant influencing factors, evaluation indicators and consequences of the quality of their relationships with SC partners.

Originality/value - This paper provides the first literature review at the intersection of RQ and SC. The research framework developed specifies the use of the previous RQ framework in the business-to-business and SC context. A critique of the existing studies is discussed and the agenda for future research is suggested.

Keywords: relationship marketing, buyer-seller relationship, relationship quality, supply chain, performance

Paper type: literature review 
This article has been published in Journal of Business and Industrial Marketing:

Qian, C., Seuring, S., \& Wagner, R. (2020). A review of interfirm relationship quality in supply chains. Journal of Business \& Industrial Marketing, in press, available online 28 March 2020. https://doi.org/10.1108/JBIM-05-2019-0199.

Emerald allows authors to deposit their Author Accepted Manuscript (AAM) under the Creative Commons Attribution Non-commercial International Licence 4.0 (CC BY-NC 4.0). The AAM is deposited under this licence and that any reuse is allowed in accordance with the terms outlined by the licence. To reuse the AAM for commercial purposes, permission should be sought by contacting permissions@emeraldinsight.com. For the sake of clarity, commercial usage would be considered as, but not limited to:

o Copying or downloading AAMs for further distribution for a fee;

o Any use of the AAM in conjunction with advertising;

o Any use of the AAM by for promotional purposes by for-profit organisations;

o Any use that would confer monetary reward, commercial gain or commercial exploitation. 


\section{Introduction}

Marketing researchers have defined relationship quality (RQ) as the relationship parties' overall evaluation of a relationship's strength (Palmatier et al., 2006). In both business practice and academic research, RQ has gained considerable attention. Many contributions to contemporary knowledge are derived by challenging the RQ between buyers and suppliers - in other words, by considering the supply chain (SC) context. The quality of the relationships formed among business partners in SCs has been considered a critical factor, as firms strive to develop a sustainable competitive advantage. Nyaga and Whipple (2011, p. 345) stated that "value creation is derived, in part, by leveraging relationships among supply chain members as 'individual businesses no longer compete as stand-alone entities' such that firms 'who can better structure, coordinate and manage their relationships' with supply chain partners can achieve a competitive advantage." Accordingly, a rich and growing stream of research has been devoted to the study of interfirm RQ in SC settings, advancing understanding of the constituents, drivers and consequences of buyer-seller RQ based on both conceptual and empirical perspectives (Wagner et al., 2010).

This paper seeks to synthesize the studies on inter-firm RQ in SCs by conducting a content analysis-based structured literature review. Specifically, we analyze the antecedents, dimensions and consequences - particularly the performance and behaviors on the level of collaborating partners - of buyer-seller RQ. This analysis is guided by a conceptual framework of RQ proposed by Athanasopoulou (2009), who developed an antecedent-RQ mediator-consequence schema by synthesizing RQ papers published in major marketing journals in the twenty years leading up to 2007. The use of this framework enables a systematic assessment, thereby providing the categorization scheme for the subsequent analysis. The framework applies to both business collaborating partners - buyers and sellers - involved in a SC relationship, and to various relationship types, industry sectors, and regions as well. Three research questions will be answered: (1) which antecedents, dimensions and consequences of RQ have been considered in existing studies on inter-firm RQ in SCs? (2) How do scholars link the consequences of RQ to the individual buyers and sellers involved in the SC relationships? (3) What are the gaps present in existing research and which directions for further investigation can be identified?

The remainder of this paper is structured as follows: in the next section, the basic terminology is defined and from the conceptual framework selected, categories for a content analysis of the literature are deductively derived. Subsequently, the research methodology applied herein is explained. Thereafter, the results of the data analyses are presented. Subsequently, the implications of the results and the limitations of the paper are discussed in detail. Finally, the paper concludes by answering the research questions posed earlier.

\section{Contextualization and conceptual framework}

\subsection{A definition of inter-firm relationship quality in supply chains}

As inter-firm RQ in SCs is the theme of our review, we will define this, in order to outline the scope of our research and thus provide a clear focus. We combine the definitions of core terms such as RQ and SC, which have been defined by marketing and SC scholars, respectively. 
Beginning with the SC context, this paper uses Mentzer et al.'s (2001, p. 4) frequently cited definition of SC as "a set of three or more entities (organizations or individuals) directly involved in the upstream and downstream flows of products, services, finances and/or information from a source to a customer." Accordingly, inter-firm relationships in a SC refer to all types of vertical relationships between organizations involved in the upstream and downstream flows, i.e., buyer-seller business relationships in this SC. Chen and Paulraj (2004) describe SCs as "a network of interdependent relationships developed and fostered through strategic collaboration with the goal of deriving mutual benefits".

To inter-firm relationships in SCs, we apply the concept of RQ, which, in general, is defined as a composite measure of the strength of the relationship between the relationship parties (Palmatier, 2008; Alejandro et al., 2011; Tan and Ndubisi, 2014). Correspondingly, we define inter-firm RQ in SCs as an overall measure of the strength of relationships between organizations directly involved in the upstream and downstream flows of products, services, finances and/or information from a source to a customer, i.e., the buyer-seller relationships in the chain, throughout all stages of relationship development and maintenance.

\subsection{Dimensions, antecedents and consequences of relationship quality}

\subsubsection{Dimensions of relationship quality}

By focusing on different types of inter-firm relationships and members' different perspectives, scholars and practitioners have defined and measured RQ in various ways. Despite the variety of conceptualization and operationalization of RQ, scholars are consistent in arguing that RQ is a second-order and holistic construct composed of several first-order dimensions capturing the different but related facets of a relationship (Palmatier et al., 2006; Nyaga and Whipple, 2011; Jiang et al., 2016). Based on the social nature of a relationship, many researchers (see Athanasopoulou, 2009) have considered trust, commitment and satisfaction as the three established dimensions of RQ. In addition, cooperation/collaboration, communication, relation-specific assets and adaptation, longterm orientation, dependence and power, have also been considered inter-firm RQ dimensions (e.g., Su et al., 2008; Čater and Čater, 2010; Obadia and Vida, 2011; Nyaga et al., 2013; Jiang et al., 2016).

Scholarly research shows three approaches for assessing inter-firm RQ in SCs: buyers' perspective; sellers' perspective; and dyadic perspective. Emphasizing the cognitive nature of RQ, Holmlund (2008) formulated a definition of perceived RQ from a dyadic perspective as a "joint cognitive evaluation of business interactions by significant individuals in both firms in the dyad. The evaluation encompasses a comparison of experienced with desired, potential, usual or previous interactions which constitute comparison standards" (p.35).

During our research, we found that, in academic discussion, the majority of scholars adopt either a buyers' or sellers' perspective to assess buyer-seller RQ. A few studies have a dyadic view and take both buyers' and sellers' perspectives into account (e.g., Lai et al., 2009; Liu et al., 2010; Nyaga et al., 2013; Sjoerdsma and van Weele, 2015). However, the SC approach has rarely been used in existing RQ studies except in one paper (Kühne et al., 2013). In the SC approach, RQ is supposed to be considered on a network level (Chen \& Paulraj, 2004). This means that the quality of buyer-seller relationships embedded in the $\mathrm{SC}$ or network should be considered in an integrative manner. Due to the lack of papers on the SC/network level, our paper focuses on the interfirm level and considers the quality of the individual buyer-seller relationships embedded in the SC. 


\subsubsection{Antecedents and consequences of relationship quality}

In addition to dimensions of RQ, scholars advance understanding of the antecedents and consequences of RQ based on both conceptual and empirical perspectives (Wagner et al., 2010). Systematically synthesizing the findings of academic studies, some scholars developed conceptual frameworks that illustrate the various types of antecedents and consequences of relationships mediated by RQ (see Palmatier et al., 2006; Athanasopoulou, 2009).

Palmatier et al.'s (2006) argument that "No single relational mediator captures the full essence of depth of a customer-seller relationship" (p. 150) forms the core of Athanasopoulou's (2009) study that focused on the global, multidimensional construct of $\mathrm{RQ}$. Basing on an analysis of papers (on B2B and B2C relationships) published in major marketing-related journals, Athanasopoulou developed a general research framework on RQ encompassing three core themes: antecedents, dimensions and consequences of RQ. The antecedents include four groups of factors: (1) characteristics of relationship parties; (2) relationship attributes; (3) offer characteristics; and (4) the environment. The consequences comprise three categories: (1) performance; (2) relational benefits; and (3) satisfaction of the parties (see Table 1).

In our paper, we employ Athanasopoulou's research framework for categorizing the antecedents and consequences of RQ, because it has the advantage of being more generalizable and comprehensive, since: (1) it considers a general perspective on the meaning of $\mathrm{RQ}$ as a holistic evaluation of relationships. Based on that, the operationalization of RQ is not restricted to certain dimensions, as it is in most RQ research, but instead covers the full set of RQ dimensions; (2) it applies to both parties buyers and sellers - involved in a relationship. For instance, in respect to the consequences of RQ, both parties' outcomes or benefits need to be considered, such as both buyers' and sellers' performance improvement and relationship intentions, etc.; (3) it covers different relationship types, industry sectors and regions that have been considered in previous research and thus it applies to all contexts.

Based on Athanasopoulou (2009)'s research framework, we deductively build categories from this framework as the foundation for the content analysis of the literature. A total of eight categories were derived: four from the antecedents of RQ (ANT), one from the dimensions of RQ (RQ), and three from the consequences of RQ (CON) (Table 1). The values in the "frequency" column indicate how many papers in our sample address the particular category. They will be explained and discussed in detail in the following sections. 
Table 1 Antecedents, RQ, consequences and their description.

\begin{tabular}{lcl}
\hline Category & Frequency & \multicolumn{1}{c}{ Description } \\
\hline $\begin{array}{l}\text { ANT: } \\
\text { Characteristics of } \\
\text { relationship parties }\end{array}$ & 38 & $\begin{array}{l}\text { Characteristics of buyers and/or suppliers including } \\
\text { variables such as similarity, reputation, size, expertise, } \\
\text { strength, the level of formalization and centralization, } \\
\text { ethical behavior and orientation, market and/or } \\
\text { relationship orientation, etc. }\end{array}$ \\
$\begin{array}{l}\text { ANT: Relationship } \\
\text { attributes }\end{array}$ & 44 & $\begin{array}{l}\text { All of the characteristics of the buyer-seller dyadic } \\
\text { relationship including the length or duration of the } \\
\text { relationship, structural or social bonds, dependence and } \\
\text { power distribution, relationship termination cost, } \\
\text { switching cost, relationship benefits, the nature and }\end{array}$ \\
& & $\begin{array}{l}\text { quality of communication, cooperation, conflict } \\
\text { handling, less opportunistic behavior, etc. }\end{array}$ \\
ANT: Offer \\
characteristics
\end{tabular}

Own illustration based on Athanasopoulou (2009).

\section{Method}

\subsection{Content-analysis based structured literature review}

Regarding the research method, a structured literature review using content analysis (Seuring and Gold, 2012) was employed. Content analysis is regarded as an effective tool for conducting literature reviews in a systematic and transparent way. "It encompasses the analysis of a set of systematically identified literature by means of content analysis and allows a rule-governed combination of quantitative and qualitative arguments and reproducibility" (Sauer and Seuring, 2017, p. 237). Its relevance to supply chain and operations management research has been noted. 
Following a process model for content analysis as explained by Seuring and Gold (2012), four steps: (1) material collection; (2) descriptive analysis; (3) category selection; and (4) material evaluation were undertaken in our study. This process model encompasses well accepted literature review process steps proposed by for example Tranfield et al. (2003) in its step (1), (2) and (4); however, it provides a more detailed approach to data extraction and synthesis based on "a rule governed, transparent and replicable definition of a category system" (Sauer and Seuring, 2017, p. 238) through step (3). This category system enables a systematic analysis and synthesis of the material against the research question. In the following sections, the adopted process model is specified for our study step by step.

\subsubsection{Material collection}

The material collection was based on a systematic search which was started with the identification of the appropriate search terms. Based on the research design and the proposed research questions, we applied two classes of search terms:

1) "relationship quality,"

2) "supply chain," "suppl*," “inter-firm," “interfirm," "inter-organizational," "interorganizational," "B2B," and "business-to-business."

The former class includes only one phrase, since RQ is an established construct in the relationship marketing research and represents the major theme of this study. The latter class encompasses several phrases, to take into account both the inter-firm setting and the SC context.

The search was conducted by using the "title, abstract, keywords" search for all combinations between these two classes of search terms. The databases selected for the systematic search were Web of Science (WOS) (www.webofknowledge.com), Elsevier (www.sciencedirect.com), and Emerald (www.emeraldinsight.com). WOS was selected, as it is regarded as having "the widest range of high quality scientific journals of all databases" (Sauer and Seuring, 2017, p. 238). Elsevier and Emerald were added to include materials which were not found by using WOS. The final result of the material collection show that an extra 13 papers (13\% of the total number of papers of the sample) were identified for further analysis by employing the Elsevier and Emerald databases.

The search began with the year 2006 and continued until 2015, representing a decade of research. The reason for this was that, during our research, we found that the topic of inter-firm RQ in SCs has gained increased attention in the last decade. This was also affirmed by the literature review conducted by Athanasopoulou (2009), who found only 38 papers on B2B RQ (including non-SC-based papers) published in marketing-related journals in the twenty years leading up to 2007. Thus, our approach aims at evaluating a decade of research in the field of inter-firm RQ in the SC settings after Athanasopoulou's (2009) literature review.

The initial search results are shown in Table 2, depicting a total of 265 papers found. Afterwards, the search results were successively refined by: (1) deleting the duplicates from various databases and then (2) manually reviewing the abstract and occasionally the main part of each article, in order to select the relevant papers for further review. Three selection notes were made for delimitation of the research:

1) To ensure reliable quality research, the review focuses on papers published in peer-reviewed journals written in English. Considering that the research of interfirm RQ in SCs involves different subject areas, no delimitations of the journal's subject areas were set.

2) According to the definition of inter-firm relationships in SCs used for this study (see section 2.1), the review focuses on buyer-seller relationships. Publications 
involving intra-organizational or horizontal inter-organizational relationships were excluded. Furthermore, as the focus is on inter-firm relationships, papers that investigate $\mathrm{B} 2 \mathrm{C}$ relationships were excluded from this research.

3) RQ has to be one of the selected article's main topics. Papers concerning RQ were considered if they met the following conditions: either the concept of RQ is explicitly introduced in the paper or it can be deduced from the main content of the paper. In the latter case, two or more dimensions of RQ must emerge as the main themes of the research even if the term "RQ" is not explicitly denominated. Consequently, papers that address only one dimension of RQ (for instance, trust, or commitment) are not taken into account because this paper regards RQ as a holistic construct composed of several dimensions.

Upon application of these delimitations, a total of 100 papers remained for further analysis ${ }^{1}$. Table 3 shows the search results after each steps of the refinement.

Table 2 The initial search results.

\begin{tabular}{lll}
\hline Search strings & $\begin{array}{l}\text { Employed } \\
\text { databases }\end{array}$ & $\begin{array}{l}\text { Search results } \\
\text { (number of papers) }\end{array}$ \\
\hline "relationship quality*" AND ("supply chain*" OR & WOS & 186 \\
"supp1*" OR "inter-firm*" OR "interfirm*" OR & Elsevier & 38 \\
"inter-organizational*" OR "interorganizational*" & Emerald & 41 \\
OR "B2B*" OR "business-to-business*") & &
\end{tabular}

265 (total)

Table 3 The search results after refinement.

\begin{tabular}{ll}
\hline Steps of the refinement & $\begin{array}{l}\text { Results of the successive } \\
\text { refinement } \\
\text { (number of papers remained) }\end{array}$ \\
\hline Elimination of duplicates from various databases & 210 \\
$\begin{array}{l}\text { Exclusion of non-journal-papers } \\
\begin{array}{l}\text { Exclusion of papers on intra-organizational, horizontal } \\
\text { inter-organizational or B2C relationships }\end{array}\end{array}$ & 208 \\
$\begin{array}{l}\text { Exclusion of papers not focusing on RQ and the papers } \\
\text { addressing only one dimension of RQ }\end{array}$ & 100 (final sample) \\
\end{tabular}

\subsubsection{Descriptive analysis}

The content of all selected papers was assessed by means of a descriptive analysis, i.e. the distribution of publications across the time period and across source journals was illustrated. Furthermore, the research methodologies applied are explained. This analysis provides a fruitful basis for the interpretation applied in the subsequent content analysis of the paper selected.

\subsubsection{Category selection}

Category selection builds the core of the content analysis approach. Categories can be built either deductively or inductively. The selected categories are used to analyse and synthesize the material against the research question. During the material analysis, the 
category system is refined in an iterative way (Seuring and Gold, 2012). In our research, we followed a two-step approach to build the categories. First, we adopted the deductive categories derived from the research framework of RQ proposed by Athanasopoulou (2009). A total of eight main categories were predefined as listed in Table 1. Next, this set of categories was complemented by defining subcategories for an in-depth understanding of the main categories. These subcategories were built during the material evaluation, which composed the fourth step of the process.

\subsubsection{Material evaluation}

In the fourth step, the set of selected papers was evaluated according to the main categories predefined in the third step. During the review process, subcategories were supplemented. Finally, the results of the evaluation were analyzed in a frequency analysis and a contingency analysis. The results of the frequency and contingency analyses address the first and second research question respectively. They were interpreted and discussed relating to the current debate on managing inter-firm relationships in SCs. Based on that, the research gaps were identified and the future research directions were suggested, which reflects the third research question.

\subsection{Frequency analysis and contingency analysis}

In order to complement the qualitative arguments related to the content analysis, quantitative arguments are provided by conducting a frequency and contingency analysis. By means of a frequency analysis, the scope of current RQ topics presented in the papers on inter-firm RQ in SCs was mapped by counting the frequency of occurrence of all the analytic categories (including the main categories and the subcategories) in the papers analyzed. The occurrence of a category was counted once for a paper analyzed if it was discussed in this paper. Thus, we consolidate what has been studied in the past and evaluate the presence and absence of topics or constructs.

A contingency analysis aims at identifying association patterns, i.e., pairs of categories which occur relatively more frequently together in one study than the product of their single probabilities (Sauer and Seuring, 2017). Based on the coding frequencies of the main categories and the subcategories compiled in the material evaluation, the phi coefficient $(\varphi)$ of each pair of categories was calculated by conducting a chi-square test. We used SPSS 24 for calculation. The phi coefficient indicates the strength of the association between two categories. A positive association with $\varphi$ exceeding 0.3 is deemed non-trivial (Hair et al., 2013). This statistically positive association means that scholars often investigated two categories in one study. The higher the phi-value, the higher the probability that two categories were studied in one paper. However, a high phivalue does not mean there is definitely a semantically positive correlation or causality between these two categories in a paper's argument. After we identify the positive associations between two categories based on the phi-value, we will justify their connection against the related literature analyzed (Sauer and Seuring, 2017). Accordingly, the contingencies offer insights into the use of relevant constructs of interfirm RQ in SC settings in the individual papers. The contingency analysis can contribute to how scholars link the constructs or tested the model within the literature sample, which provides a second level of analysis based on the content analysis. 


\subsection{Methodological rigor}

To ensure the production of high-quality research, validity, reliability and repeatability issues related to the content analysis were considered following Seuring and Gold (2012). In order to ensure construct validity, the main analytic categories were deductively built from the extant research framework selected from related literature. Each paper was coded according to all categories, which provides internal validity in the subsequent data analysis. The external validity was ensured as the research process was conducted in a rigorous and transparent manner as described here. Regarding repeatability, the transparency is guaranteed by detailed documentation of the method applied and recording all the steps taken during the research process (see sections 3.1.1 to 3.1.4). To carry out the coding, MAXQDA 12 was used and all of the coded data taken from the papers analyzed were recorded, thereby allowing for replication. SPSS 24 was used for calculating contingencies. The most challenging issue of the content analysis was reliable coding, which would ideally be ensured by joint coding among several researchers. This was done for a subset of the sample (42 papers), which was separately coded by two coders.

\section{Analysis and results}

\subsection{Descriptive analysis}

The results of the descriptive analysis concerning the distribution of publications across the time period, the source journal, and the applied research method are elaborated and discussed in the following sections.

\subsubsection{Publication years}

Assessing the distribution of publications across the time period, the results indicate a two-stage increase of the number the publications across the time period from 2006 to 2008 and from 2009 to 2011 with the respective publication peaks in 2008 (15) and 2011 (16)(Figure 1). After 2012, the number of papers published annually remained at a consistent level with more than ten papers being published per year by the end of 2015 .

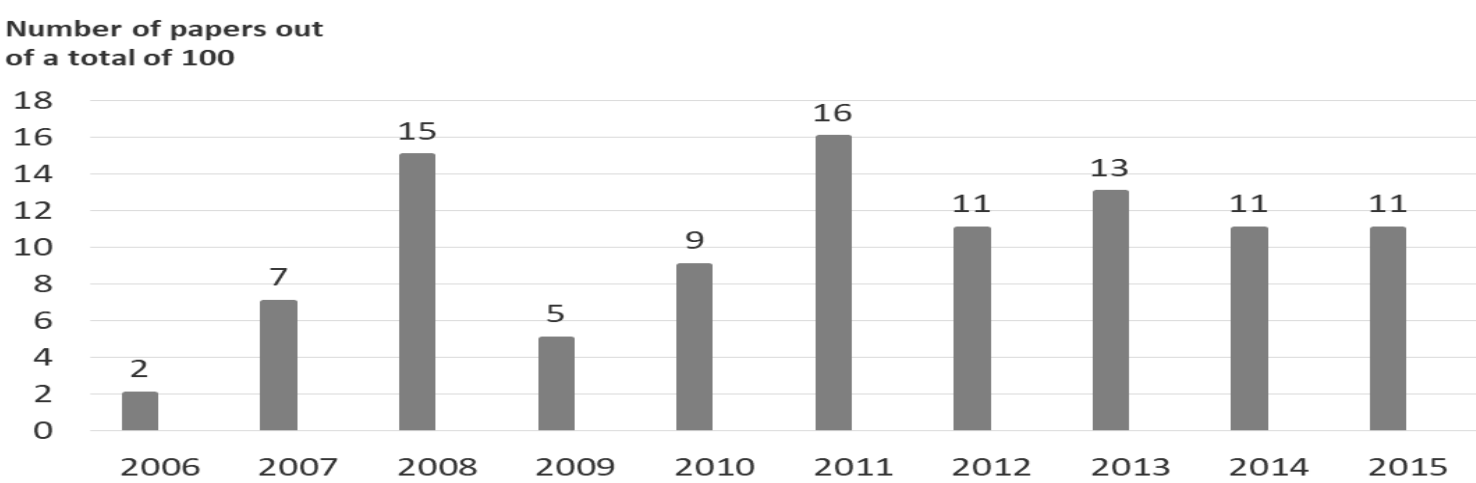

Figure 1. Distribution of the publications across the time period.

\subsubsection{Source journals}

The sample of 100 papers used in this research was derived from 47 journals. Over half of the papers (51) were published in marketing-related journals, whereas SC-related journals only contributed 12 papers to this study. The remaining papers (37) were published in other journals. Industrial Marketing Management (22), Journal of Business 
\& Industrial Marketing (10), and Journal of Business Research (9) are the top three source journals containing over 40 percent of the papers reviewed.

\subsubsection{Research methodology applied in the papers}

Research on inter-firm RQ in the SC context is of an empirical nature and strongly dominated by survey papers (92) which basically test conceptual models proposing relations between diverse variables. Papers employing qualitative approaches are scarce and only seven present case studies (i.e., Aminoff and Tanskanen, 2013; Holmlund, 2008; Lo, 2015; Myhal et al., 2008; Richard et al., 2007; Sjoerdsma and van Weele, 2015; Zander and Beske, 2014). Only one paper is of a conceptual nature aiming to explain the process of value creation by building relationships in which RQ has a mediating effect (Dorai and Varshney, 2012).

\subsection{Frequency analysis regarding the analytic categories}

The occurrence frequencies of categories (including main categories and subcategories) are described regarding the following aspects: the antecedents, dimensions and consequences of $\mathrm{RQ}^{2}$.

\subsubsection{Antecedents of $R Q$}

Regarding the antecedents of RQ, the results of the frequency analysis indicate that roughly one in three studies discuss the characteristics of the relationship parties (38), particularly the sellers' characteristics (34), such as its similarity, reputation and size, knowledge, skill, resources, capacity, experience, overall competency, performance, market or relationship orientation, ethical behavior and orientation, and top manager/supply manager's behavior. In contrast, the buyers' characteristics (7) have rarely been addressed. They include the buyers' reputation, size, financial attractiveness, market orientation, collaborative behavior and orientation. The dominance of the suppliers' characteristics as the antecedents of RQ can be attributed to the predominance of the buyers' perspective, which has been applied in 60 of 100 papers analyzed. In contrast, the supplier perspective has been employed in only 23 papers.

Furthermore, nearly half of the analyzed papers study the relationship attributes (44) influencing RQ. The attributes vary widely in those papers; however, some of them have gained more attention than others. They are power and dependence (e.g., Chu and Wang, 2012; Gyau et al., 2011; Lai et al., 2013; Zaefarian et al., 2015); the nature and quality of communication (e.g., Barnes et al., 2015; Chu and Wang, 2012; Gyau et al., 2011; Sarmento et al., 2015); and inter-personal relationships and social bonds (e.g., Alejandro et al., 2011; Barnes et al., 2011; 2015; Palmatier et al., 2008; Rauyruen and Miller, 2007). The categories offer characteristics (10), and the environment (2) play only minor roles in the papers reviewed.

\subsubsection{Dimensions of $R Q$}

All of the articles analyzed address the category: RQ. This is not surprising as it is one of the core search terms applied. Most of the authors defined and operationalized RQ explicitly in their papers. For example, Fynes et al. (2008) stated that the major dimensions of RQ include trust, adaptation, communication and cooperation. They defined and measured them as the four first-order constructs of RQ. We coded the dimensions: conflict and communication as the two dimensions of RQ in Williams et al. (2015), because the authors used these as the measurement items of RQ in their questionnaire. In a few studies, the term RQ was mentioned but not conceptualized (e.g., 
Barnes et al., 2011; Baxter, 2012), or the term RQ was not denominated (e.g., Wu et al., 2012). In such cases, the coding of the RQ dimensions was based on the content of the paper or the structure of the model used. For example, we coded satisfaction as a dimension of RQ in Barnes et al. (2011) according to the text "satisfaction is a subjective measure of relationship quality" (p. 513). Further, we coded the mediator variables: trust and commitment as the dimensions of RQ in Wu et al. (2012) according to the structure of the model used in the paper. It should be noted that four papers in our sample investigate RQ as the moderator (Lai et al., 2009; Richey et al., 2010; Beitelspacher et al., 2012; Dorai and Varshney, 2012). We include them in our sample despite their deviation from the applied conceptual framework in which RQ is positioned as a mediator.

As a result, a total of 17 dimensions of RQ were identified. In Table 4 we summarize the most commonly used definitions and descriptions of eight dimensions that were addressed in more than ten percent of the papers analyzed. It lists trust (78), commitment (64), and relationship satisfaction (49) as the three items mentioned most frequently. Cooperation/collaboration (19), communication (18), relation-specific assets and adaptation (12), long-term orientation (11), and dependence and power (11) were considered RQ dimensions, but, have received much less attention than trust, commitment and satisfaction. The remaining dimensions are not included in the table because they were mentioned less than ten times in the sample.

Table 4 Dimensions of RQ addressed in the sample of 100 papers.

\begin{tabular}{|c|c|c|}
\hline $\begin{array}{l}\text { Dimensions } \\
\text { (Occurrence } \\
\text { frequency) }\end{array}$ & Description & References \\
\hline
\end{tabular}

Trust (78)

Commitment

Relationship satisfaction (49)

Cooperation/ Collaboration (19)
Confidence in the reliability and integrity of a relationship partner.

An enduring desire to maintain a valued relationship (or characterized by the intention to maintain long-term relationships) which is implicit in the expectation of realizing long-term benefits. It will result in a desire to develop a stable relationship, a willingness to make shortterm sacrifices to maintain the relationship, and confidence in the stability of the relationship.

A positive affective state resulting from the appraisal of all aspects of a firm's working relationship with its partner. It is a result of a comparison process between perceived performance and one or more comparison standards, such as expectations.

An orientation that reflects a spirit of willingness by one organization to work with another, or all activities undertaken jointly or in collaboration with others that are directed towards common interests or achieving rewards.
Palmatier et al., 2006

Palmatier, 2008; Čater and Čater, 2010; Liu, et al., 2010; Payan et al., 2010; Chang et al., 2012b; Lee et al., 2013

Chu and Wang, 2012; Sarmento et al., 2015

Su et al., 2008; Mysen and Svensson, 2010; Payan et al., 2010; Song et al., 2012; Zander and Beske, 2014

Source: Own illustration.

(Continued) 
Table 4 Dimensions of RQ addressed in the sample of 100 papers (continued).

\begin{tabular}{|c|c|c|}
\hline $\begin{array}{l}\text { Dimensions } \\
\text { (Occurrence } \\
\text { frequency) } \\
\end{array}$ & Description & References \\
\hline $\begin{array}{l}\text { Communication } \\
\text { (18) }\end{array}$ & $\begin{array}{l}\text { The formal and informal sharing of meaningful } \\
\text { and timely information between partners. }\end{array}$ & $\begin{array}{l}\text { Su et al., 2008; Leonidou } \\
\text { et al., } 2013\end{array}$ \\
\hline $\begin{array}{l}\text { Relations- } \\
\text { specific assets/ } \\
\text { adaptation (12) }\end{array}$ & $\begin{array}{l}\text { The dedicated activities that are tailored for use } \\
\text { between specific organizations in a relationship } \\
\text { and, for instance, concern the behavioral or } \\
\text { structural modifications carried out by one firm } \\
\text { to meet the specific needs of another firm. }\end{array}$ & $\begin{array}{l}\text { Čater and Čater, 2010; } \\
\text { Payan et al., 2010; } \\
\text { Svensson and Mysen, } \\
\text { 2011; Sjoerdsma and van } \\
\text { Weele, } 2015\end{array}$ \\
\hline $\begin{array}{l}\text { Long-term } \\
\text { orientation (11) }\end{array}$ & $\begin{array}{l}\text { It is associated with the expectation of } \\
\text { relationship continuity and the focus on long- } \\
\text { term goals in the relationship. }\end{array}$ & $\begin{array}{l}\text { Jiang et al., 2011; Jiang et } \\
\text { al., } 2016\end{array}$ \\
\hline $\begin{array}{l}\text { Dependence and } \\
\text { power (11) }\end{array}$ & $\begin{array}{l}\text { Dependence refers to the extent to which one } \\
\text { party needs to maintain the relationship with the } \\
\text { partner in order to achieve the desired goals. } \\
\text { Firms have power to the extent that other firms } \\
\text { depend on them for resources, including } \\
\text { financial, expertise, information, services, } \\
\text { legitimacy or status, and one firm's possession } \\
\text { of attributes or rightful claims (e.g., contract } \\
\text { obligations) that may motivate its partners to } \\
\text { comply. One firm may use its power to influence } \\
\text { the other firm to act in a manner that it would } \\
\text { not have otherwise. }\end{array}$ & $\begin{array}{l}\text { Jiang et al., 2011; } \\
\text { Svensson and Mysen, } \\
\text { 2011; Chang et al., 2012a; } \\
\text { Lai et al., 2013; Nyaga et } \\
\text { al., } 2013\end{array}$ \\
\hline
\end{tabular}

Source: Own illustration.

\subsubsection{Consequences of $R Q$}

Among the three categories of RQ consequences, performance outcomes (42) attracted the same amount of attention as relational benefits (42) (see Table 1). Notably, the satisfaction of both parties (11) is not as frequently addressed as the consequences mentioned above. Instead, relationship satisfaction has often been considered one of the dimensions of RQ (49).

Concerning the performance outcomes, four subcategories were identified: buyer performance; supplier performance; financial and market performance; and non-financial performance. We distinguish between buyers' performance and suppliers' performance, which have been regarded as the major constituents of the performance outcomes of managing buyer-seller relationships in SC related frameworks (e.g., Chen and Paulraj, 2004). The results of the frequency analysis show that among the RQ papers selected buyer performance outcomes (29)(e.g., Barnes et al., 2011, 2015; Fynes et al., 2008; Obadia and Vida, 2011) have been studied slightly more often than supplier performance outcomes (22)(e.g., Gounaris and Tzempelikos, 2014; Palmatier, 2008; Obadia and Vida, 2011).

Further, we differentiate financial and market performance measures from nonfinancial performance measures, which has been considered in some of the papers analyzed, but has been inconsistently operationalized (e.g., Lahiri and Kedia, 2011; Chang et al., 2012a; Gounaris and Tzempelikos, 2014). In our research, we define 
financial and market performances, which has been addressed in 34 papers, as the exhibition of monetary and market performances of a firm in terms of sales, sales growth, profit, cost, return on investment (ROI), market share, market share growth (e.g., Barnes et al., 2015; Gounaris and Tzempelikos, 2014; Kim, et al., 2011; Lai et al., 2013). Nonfinancial performances, which have been studied in 22 papers, refer to a firm's performance in terms of product/service quality (e.g., Fynes et al., 2008; Han and Sung, 2008; Nyaga and Whipple, 2011; Sjoerdsma and van Weele, 2015), process efficiency (e.g., Fynes et al., 2008; Gounaris and Tzempelikos, 2014; Han and Sung, 2008; Sheu, 2015), innovation capability and know-how development (e.g., Chang et al., 2012b; Fang et al., 2011; Gounaris and Tzempelikos, 2014), or environmental and/or social performances (e.g., Sheu 2015).

Looking at the relational benefits as the RQ consequences, four subcategories were identified: buyers' relationship intention; suppliers' relationship intention; relationship persistence; and relationship intensity. Buyers' and suppliers' relationship intention refer to a buying firm's intention to deal with the supplier relationship (e.g., Čater and Čater, 2010; Rauyruen and Miller, 2007) or a supplying firm's intention to deal with the buyer relationship (e.g., Baxter and Kleinaltenkamp, 2015), respectively. The results of the frequency analysis show that discussions on the buyers' relationship intention (34) are nearly triple those on the suppliers' relationship intention (13). Relationship persistence is synonymous with the term relationship continuity which represents a firm's propensity to continue or leave an extant relationship with its relationship partner (e.g., Cater and Čater, 2010; Leonidou et al., 2013; Sarmento et al., 2015; Su et al., 2008; Ulaga and Eggert, 2006). This has attracted more attention (28) from scholars than relationship intensity (22), which represents a firm's propensity to enhance or undermine an extant relationship with its relationship partner, including its relationship frequency and diversity and the extent to which a firm will or intends to make relation-specific investments, to share and transfer knowledge, to jointly act, to integrate, etc. (e.g., Baxter and Kleinaltenkamp, 2015; Johnston et al., 2012; Lai et al., 2013; Nyaga and Lynch, 2013; Sjoerdsma and van Weele, 2015; Su et al., 2008).

\subsection{Contingency analysis}

The results of the contingency analysis indicate three groups of contingencies among the subcategories within three main categories: RQ; CON: performance; and CON: relational benefits. Table 5 lists all category pairs with $\varphi>0.3$, which means that two categories in a pair have often been investigated in one study. In addition, the observed relative occurrence and the calculated relative probability of occurrence of category pairs are reported.

As can be seen in the table, all observed relative occurrence of category pairs are below $25 \%$, except the one for trust and commitment (59\%). It is expected that trust frequently occurs alongside commitment, as they are the two most frequently cited dimensions of RQ (see Table 4). Assessing the related papers, we found that many scholars considered both trust and commitment as first-order constructs of inter-firm RQ in SCs (e.g., Fang et al., 2011; Fynes et al., 2008; Lai et al., 2009). Some scholars have also confirmed the significant positive correlation between trust and commitment (e.g., Ulaga and Eggert, 2006; Wu et al., 2012; Wu et al., 2015). In addition, cooperation and relation-specific assets and adaptation were frequently used together as first-order constructs of inter-firm RQ in SCs (e.g., Fynes et al., 2008; Song et al., 2012). Although the observed occurrence of this category pair is only ten, this is high, as only 12 papers discuss relationship-specific assets and adaptation. Some scholars have also confirmed the positive correlation 
between cooperation and firm's relationship-specific adaptation (e.g., Leonidou et al., 2011). Unexpectedly, the occurrence frequencies of other category pairs within the main category: RQ are relative lower, and thus no other significant contingencies were identified. This indicates the heterogeneity of the research and a lack of consistency of which dimensions constitute inter-firm RQ in SCs.

Table 5 Results of the contingency analysis $(n=100)$.

\begin{tabular}{|c|c|c|c|c|c|c|}
\hline Constructs & Phi-Coefficient & $\begin{array}{c}\text { Approximate } \\
\text { significance }\end{array}$ & $\begin{array}{c}\text { Exact significance } \\
\text { (1-sided) }\end{array}$ & $\begin{array}{c}\text { Exact significance } \\
\text { (2-sided) }\end{array}$ & $\begin{array}{c}\text { Observed } \\
\text { frequency (\%) }\end{array}$ & $\begin{array}{c}\text { Expected } \\
\text { frequency (\%) }\end{array}$ \\
\hline Trust - commintment & 0,457 & 0 & 0 & 0 & 59 & 49,9 \\
\hline Cooperation - relations specific assets and adapation & 0,606 & 0 & 0 & 0 & 10 & 2,3 \\
\hline Financial and market performance - Non-financial performance & 0,449 & 0 & 0 & 0 & 16 & 7,3 \\
\hline cost - sales & 0,502 & 0 & 0 & 0 & 11 & 3,5 \\
\hline cost - profit & 0,439 & 0 & 0 & 0 & 9 & 2,9 \\
\hline cost - processes' efficiency & 0,448 & 0 & 0 & 0 & 7 & 1,8 \\
\hline cost - product/service quality & 0,421 & 0 & 0 & 0 & 7 & 2 \\
\hline market share - sales & 0,601 & 0 & 0 & 0 & 12 & 3,2 \\
\hline market share - profit & 0,613 & 0 & 0 & 0 & 11 & 2,7 \\
\hline Sales - profit & 0,765 & 0 & 0 & 0 & 17 & 4,4 \\
\hline Sales - processes' efficiency & 0,383 & 0 & 0,001 & 0,001 & 8 & 2,8 \\
\hline Sales - product/service quality & 0,354 & 0 & 0,002 & 0,002 & 8 & 3 \\
\hline profit - processes' efficiency & 0,37 & 0 & 0,001 & 0,001 & 7 & 2,3 \\
\hline processes' effiency - product/service quality & 0,681 & 0 & 0 & 0 & 9 & 1,6 \\
\hline Supplier performance -financial and market performance & 0,425 & 0 & 0 & 0 & 16 & 7,6 \\
\hline Supplier performance - non-financial performance & 0,418 & 0 & 0 & 0 & 12 & 4,8 \\
\hline Buyer performance - financial and market performance & 0,518 & 0 & 0 & 0 & 13 & 4,5 \\
\hline Buyer performance - non-financial performance & 0,608 & 0 & 0 & 0 & 17 & 5,9 \\
\hline Supplier's relationship intention - relationship persistence & 0,39 & 0 & 0 & 0 & 10 & 3,9 \\
\hline Supplier's relationship intention - relationship intensity & 0,412 & 0 & 0 & 0 & 9 & 3,1 \\
\hline Buyer's relationship intention - relationship persistence & 0,699 & 0 & 0 & 0 & 24 & 9,2 \\
\hline Buyer's relationship intention - relationship intensity & 0,603 & 0 & 0 & 0 & 19 & 7,3 \\
\hline
\end{tabular}

Note:

1. Phi-Coefficient: Measure of association within category pairs, varying from 0 (no association) to 1 (complete association) or -1 (complete inverse association), $\mathrm{Phi}>0.3$ : a non-trivial relation

2. Approximate significance: Statistical significance of phi, with $\mathrm{p}<=.001$ (highly significant), $\mathrm{p}<=.01$ (very significant) and $\mathrm{p}<=.05$ (significant)

3. Exact significance (1-sided): Statistical significance of association within category pairs, with $\mathrm{p}<=.001$ (highly significant), $\mathrm{p}<=.01$ (very significant) and $\mathrm{p}<=.05$ (significant)

4. Observed frequency $(\%)$ : observed relative occurrence of category pairs (in $\%$ )

5. Expected frequency (\%): Calculated relative probability of occurrence of category pairs (in $\%$ ) by multiplying the observed single relative occurrence of category pairs (in \%)

Within the main category: OUT: Performance, while supplier and buyer performance frequently occur alongside financial and market performances and non-financial performances, the results of the contingency analysis do not reveal a frequent cooccurrence of supplier and buyer performance. These findings do not come as a surprise, given that most authors of the papers used in our sample base their research on the buyers' perspective, thereby studying the effect of a buyer's perception of RQ on its own performance. Alternatively, they focus on the suppliers' perspective, discussing a supplier's perception of RQ on its performance. Consequently, performance of the buyers and the suppliers are not normally found as the consequences of RQ in the same paper. Only one paper used two independent samples (a buyer sample and a supplier sample) to investigate the effect of RQ on both the buyer and supplier performance (Nyaga and Whipple, 2011). This reveals the lack of buyer-seller RQ research, aiming at analyzing and comparing the perspectives of buyers and sellers in one study.

In addition, we found a frequent occurrence of financial and market performances in combination with non-financial performances $(\varphi=0.449)$ as well as a frequent occurrence of some performance metrics, for instance, cost and process efficiencies $(\varphi=0.448)$. These indicate that financial and market performances have often been measured in conjunction with non-financial performance by scholars who investigated the effect of 
perceived RQ on performances, and that some metrics were often used together in the same study (Kim et al., 2011; Lee et al., 2013; Nyaga and Whipple, 2011; Sheu, 2015; Tan and Ndubisi, 2014). Some scholars have also analyzed the relationship between firms' financial and market performance and their non-financial performance resulting from the buyer-seller relationship. Examples are: (1) the effect of logistics services' performance on financial performance (Richey et al., 2010); (2) the positive effect of innovativeness on financial return (Kim et al., 2011); and (3) the positive effect of capability of building capabilities through relationships on market effectiveness (Lee et al., 2013).

Finally, we found that within the main category: OUT: Relational benefits, suppliers' and buyers' relationship intention respectively occur alongside relationship persistence and relationship intensity frequently. The missing contingency between buyer and supplier relationship intentions also reveals the lack of scholars' attempt to analyze and compare the buyer and supplier perceptions with respect to the effect of RQ in one study.

\section{Discussion}

\subsection{Discussion and research agenda}

This literature review provides an in-depth account of current research in the field of inter-firm RQ in SC settings. This paper contributes to contemporary knowledge on relationship marketing by mapping the scope of antecedents, dimensions and consequences of inter-firm RQ in SCs. Based on this, we develop a research framework of inter-firm RQ in SCs (Figure 2), which specializes Athanasopoulou's (2009) RQ framework in the $\mathrm{B} 2 \mathrm{~B}$ and $\mathrm{SC}$ context. This specification reinforces the relevance of distinguishing relationship marketing in the B2B and B2C settings, which has been mentioned, but has not been specified in previous literature reviews (Palmatier et al., 2006; Athanasopoulou, 2009).

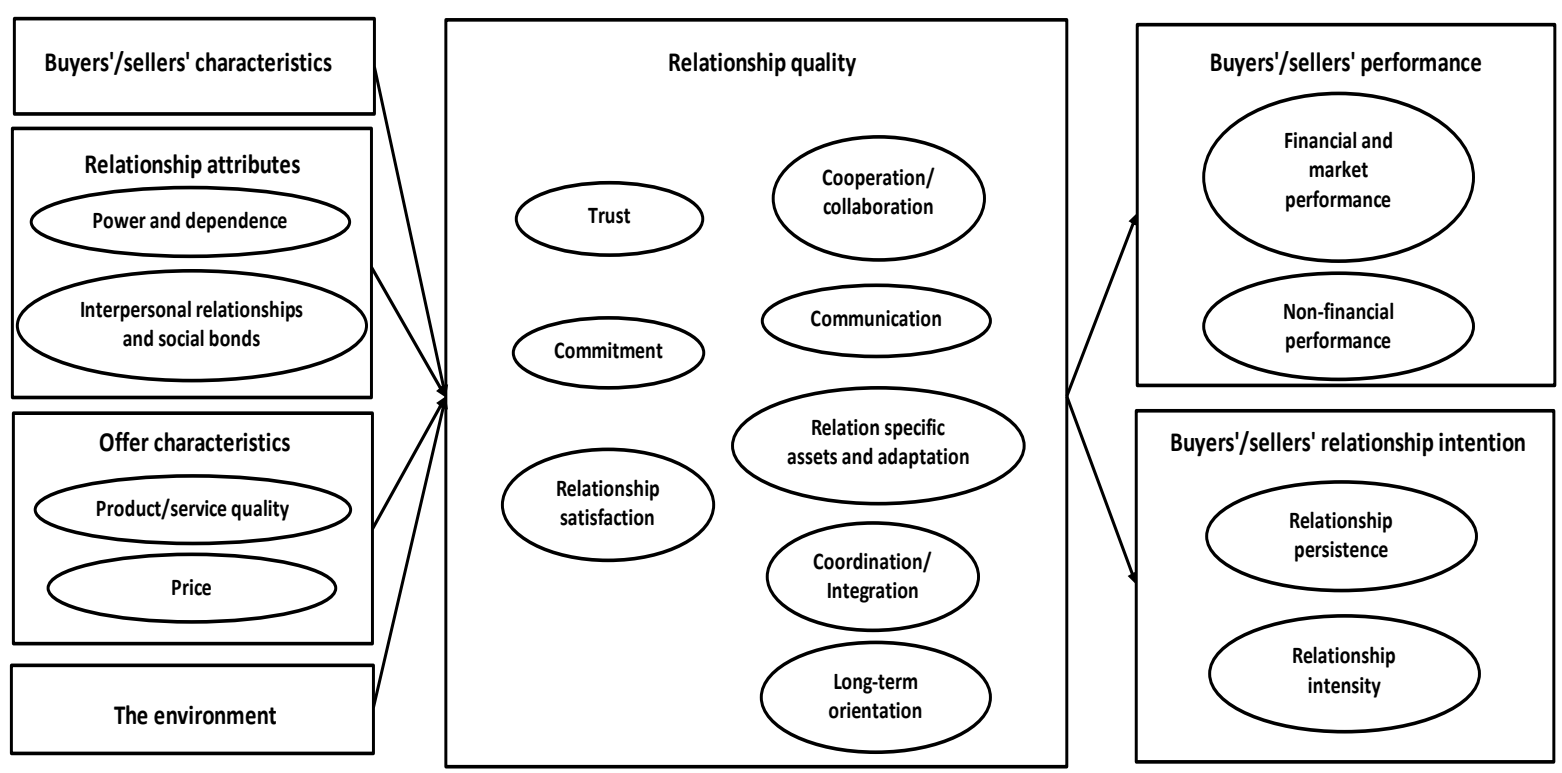

Figure 2. Research framework of inter-firm RQ in SCs.

We follow Athanasopoulou's antecedent-RQ-consequences structure to develop a research framework of inter-firm RQ in SCs. Under the main category RQ, we note the relevant dimensions of inter-firm RQ, which has been addressed in the analyzed papers. In addition, we keep the four categories of antecedents from Athanasopoulou's 
framework, as all of them have more or less been discussed in the analyzed papers. We adopt two from the three categories of consequences: performance and relationship intention from Athanasopoulou's framework, while placing satisfaction of the two parties in the category: RQ. We distinguish the consequences in respect to buyers and sellers. We consider this specification significant in the B2B and SC context, as the goal of managing buyer-seller relationships in SCs is to achieve mutual benefits (e.g., Chen and Paulraj, 2004). Subsequently, we discuss the developed framework in detail.

In respect to the dimensions that constitute inter-firm RQ in SC settings, the results of the frequency analysis support the findings of relationship marketing researchers who indicated that trust, commitment and relationship satisfaction are the three established measures of RQ (Ulaga and Eggert, 2006; Athanasopoulou, 2009; Nyaga and Whipple, 2011; Lai et al., 2013; Sarmento et al., 2015). This does not support the measurement models proposed by some scholars who exclude trust and/or commitment in the measurement of RQ (Jiang et al., 2016).

The findings of our study show that in recent research, some SC scholars have considered and highlighted the use of dimensions such as communication, coordination, cooperation and relationship specific adaptation in evaluating buyer-seller RQ, instead of solely employing the affective dimensions such as trust, commitment and satisfaction (Fynes et al., 2008; Sjoerdsma and van Weele, 2015; Su et al., 2008; Shin et al., 2018). In providing a comprehensive examination of inter-firm RQ issues in SC settings, there is a need for future research to include both the attitudinal and behavioral dimensions of RQ in the model, as illustrated in Figure 2.

A notable inconsistency in the papers analyzed is that constructs such as trust, commitment, satisfaction, cooperation, communication, relationship specific investment and adaptation, long-term orientation, power and dependence, have repeatedly occurred as antecedents or dimensions or consequences of RQ. For example, satisfaction has been regarded as a dimension (Wagner et al., 2010), or a consequence (Mysen and Svensson, 2010) by different scholars. Furthermore, the level of cooperation between SC partners has been considered an antecedent (Sheu, 2015), a dimension (Čater and Čater, 2010), or a consequence of RQ (Nyaga et al., 2013; Wu et al., 2015). This inconsistency was also pointed out in Holmlund's (2008) study, yet it seems not to have been resolved in recent research. In order to make causal inference, scholars have been conducting longitudinal research using the life-cycle perspective instead of applying a cross-sectional design. However, there has yet to be a longitudinal study in the sample of papers reviewed, which constitutes a research gap in this area. Relationships are dynamic in nature. Studies that help improving the understanding of the continuous development of relationships in different stages of relationship development and maintenance offer a valuable direction for future investigation.

On the other side, many scholars used a second-order model to measure RQ in the papers analyzed (Fynes et al., 2008; Su et al., 2008). However, there is a lack of consistency of which first-order constructs constitute the second-order RQ. By using a second-order model, scholars have not analyzed the causality between the first-order dimensions, for example, trust, commitment, satisfaction, cooperation and communication. Moreover, scholars have examined the aggregate effect of RQ (Fynes et al., 2008). This however, cannot clarify which role the individual underlying factors of RQ play in facilitating relationships and which factors are more effective with specific values on other factors. Providing answers to these questions would help managers improve their understandings of how SC relationships work in various contexts and how to gain relationship-building benefits by effectively using these relationships. Endeavoring to clarify the role of the different RQ dimensions and the relationship- 
building path leading to benefits in various contexts, we suggest that future researchers abandon second-order models and focus on the individual underlying dimensions of RQ.

Further, the contingency analysis explores some statistically significant links and gaps within the literature sample we used. The identified contingencies reveal that scholars tend to link the perception of high-quality relationships with SC partners to the improvement of performance (including financial and market performance as well as nonfinancial performance) from both buyers' and suppliers' perspectives. In addition, scholars have often linked the perception of high-quality relationships to both the buyers' and suppliers' propensity to continue or enhance the SC relationship. However, we observed in our sample of the papers analyzed that few authors examined and compared the buyers' and suppliers' perceptions of the RQ outcomes in one study (Nyaga and Whipple 2011; Nyaga et al., 2013). Evidence has already shown that buyers and suppliers perceive relationships differently (Nyaga et al., 2013). In addition, the buyer and supplier perspectives differ in regard to both the facilitators and the barriers of buyer-supplier relationships (Kim et al., 2011). Accordingly, we propose that the perceptions of buyers and suppliers with respect to the outcomes of RQ are somewhat different. In order to figure it out, there is a need for future research to collect and compare data from both buyers and sellers in one study. For instance, it would be meaningful to examine the path of the RQ factors leading to improved performance, matching the buyers' and sellers' perspective. This would help us improve the understanding of the common points and differences of the buyer and supplier perceptions in respect to the primary drivers of relationship outcomes. The comparison is particularly critical for examining whether both parties in SC relationships are able to achieve mutual benefits through developing and maintaining high-quality relationships (Nyaga et al., 2010).

\subsection{Limitations}

Despite its contributions, we acknowledge that there are several limitations in the design of this study. The main limitation lies in the framework selection and consequently the category building for the content analysis. The framework proposed by Athanasopoulou (2009) focuses on the mediator structure and neglects the effects of moderators. Further research that considers the control variables and examines their moderating effect would be interesting. Besides, for category building, we followed the structure: antecedents, mediators and consequences, and did not resolve the overlaps of categories that occur in different dimensions of this structure, for example, among relationship attributes (antecedents), RQ (mediator), and relational benefits (consequences). The results of contingency analysis using this approach could differ from those resolving all of the overlaps.

\section{Conclusion}

This paper conducts a structured review of English-speaking peer-reviewed journal publications regarding inter-firm RQ in SC settings in the last decade, employing a content analysis approach, guided by a conceptual framework of RQ. The main findings and contributions of this study are summarized as follows, reflecting the three research questions proposed at the beginning of this paper.

First, this paper maps the scope of the antecedents, dimensions and consequences of buyer-seller RQ discussed in the scholarly research. We found the important dimensions for evaluating the quality of a firm's relationships with its SC partners to include dimensions that describe both firms' attitude and behaviors towards the SC relationship. Various factors, particularly the relationship parties' characteristics, the distribution and 
use of power as well as the interpersonal relationships may affect the inter-firm RQ. Besides marketing-related factors such as maintaining and enhancing the business relationship, increasing performance is the main consequence of firms' building highquality relationships with SC partners.

Second, this paper shows that scholars have connected buyer-seller RQ to both buyers' and sellers' performance and their relationship intentions. However, whether buyers and sellers perceive the outcomes of a business relationship more similarly or differently has rarely been studied.

Third, this paper identifies the research gaps and suggests the following directions for future research:

1. For evaluating the quality of a firm's relationships with its SC partners, scholars have primarily focused on the attitudinal dimensions, i.e., trust, commitment and relationship satisfaction, while the dimensions (e.g., communication, collaboration, coordination, integration, investment, etc). need more attention from scholars and practitioners who manage SC relationships.

2. Relationships are dynamic in nature. The longitudinal research and the life-cycle perspective are needed for future research, aiming to improve our understanding of the continuous development of relationships, and the relationships of various RQ dimensions in different stages of relationship development and maintenance.

3. The use of the second-order RQ models limit scholars' ability to clarify the role of the individual underlying factors in facilitating relationships and generating relationship-building benefits. A suggestion for future researchers would be that they abandon the second-order model and focus on the relationships between and the effects of the individual underlying dimensions of inter-firm RQ in SCs.

4. To measure the performance outcomes of RQ, financial and market performances have attracted more attention than non-financial performances. Future research pursuing a more rigorous measurement of the output performance of RQ is needed.

5. Buyers and sellers may perceive RQ and the drivers as well as outcomes of RQ differently. Research that aims to investigate and compare the buyer and seller perspectives in one study is particularly valuable.

6. Thus far, there has been little integration of RQ and SC research. Linking these two concepts would enable a new and more comprehensive examination of the issues of business relationships or networks.

Overall, this study provides detailed insights into inter-firm RQ in the SC settings and uncovers a range of research gaps present in the current literature.

\section{Notes}

1 A list of the 100 papers contained in the literature review is provided in http://dx.doi.org/doi:10.17170/kobra-20200117939

2 A table of the referenced papers assigned to each of the analytic categories is provided in http://dx.doi.org/doi:10.17170/kobra-20200117939

\section{References}

*Alejandro, T.B., Souza, D.V., Boles, J.S., Ribeiro, Á.H.P. and Monteiro, P.R.R. (2011), “The outcome of company and account manager relationship quality on loyalty, relationship value and performance", Industrial Marketing Management, Vol. 40 No. 1, pp. 36-43.

*Aminoff, A. and Tanskanen, K. (2013), "Exploration of congruence in perceptions of buyer-supplier attraction. A dyadic multiple case study”, Journal of Purchasing and Supply Management, Vol. 19 No. 3, pp. 165-184. 
Athanasopoulou, P. (2009), "Relationship quality. A critical literature review and research agenda", European Journal of Marketing, Vol. 43 No. 5/6, pp. 583-610.

*Barnes, B.R., Leonidou, L.C., Siu, N.Y.M. and Leonidou, C.N. (2015), "Interpersonal factors as drivers of quality and performance in Western-Hong Kong interorganizational business relationships", Journal of International Marketing, Vol. 23 No. 1, pp. 23-49.

*Barnes, B.R., Yen, D. and Zhou, L. (2011), "Investigating guanxi dimensions and relationship outcomes: Insights from Sino-Anglo business relationships”, Industrial Marketing Management, Vol. 40 No. 4 , pp. 510-521.

*Baxter, R. and Kleinaltenkamp, M. (2015), "How relationship conditions affect suppliers' resource inputs", Australasian Marketing Journal, Vol. 23 No. 2, pp. 117-123.

*Beitelspacher, L.S., Tokman, M., Adams, F.G. and Richey, Jr, R.G. (2012), "Retail service-based operant resources and market performance", The international Journal of Logistics Management, Vol. 23 No. 3, pp. 408-434.

*Čater, T. and Čater, B. (2010), "Product and relationship quality influence on customer commitment and loyalty in B2B manufacturing relationships", Industrial Marketing Management, Vol. 39 No. 8, pp. 1321-1333.

*Chang, H.H., Lee, C.-H. and Lai, C.-Y. (2012a), "E-Service quality and relationship quality on dealer satisfaction. Channel power as a moderator", Total Quality Management \& Business Excellence, Vol. 23 No.7-8, pp. 855-873.

*Chang, M.-L., Cheng, C.-F. and Wu, W.-Y. (2012b), "How buyer-seller relationship quality influences adaptation and innovation by foreign MNC's subsidiaries", Industrial Marketing Management, Vol. 41 No. 7, pp. 1047-1057.

Chen, I.J. and Paulraj, A. (2004), "Towards a theory of supply chain management. The constructs and measurements", Journal of Operations Management, Vol. 22 No. 2, pp. 119-150.

*Chu, Z. and Wang, Q. (2012), "Drivers of relationship quality in logistics outsourcing in china”, Journal of Supply Chain Management, Vol. 48 No. 3, pp. 78-96.

*Dorai, S. and Varshney, S. (2012), "A multistage behavioural and temporal analysis of CPV in RM", Journal of Business \& Industrial Marketing, Vol. 5, pp. 403-411

*Fang, S.-R., Chang, Y.-S. and Peng, Y.-C. (2011), "Dark side of relationships. A tensions-based view", Industrial Marketing Management, Vol. 40 No. 4-5, pp. 774-784.

*Fynes, B., de Búrca, S. and Mangan, J. (2008), "The effect of relationship characteristics on relationship quality and performance", International Journal of Production Economics, Vol. 111 No. 1, pp.56-69.

*Richey, Jr, R.G., Tokman, M. and Dalela, V. (2010), "Examining collaboration supply chain service technologies: a study of intensity, relationships, and resources", Journal of Academy of Marketing Science, Vol. 38 No. 1, pp.71-89.

*Gounaris, S. and Tzempelikos, N. (2014), "Relational key account management: Building key account management effectiveness through structural reformations and relationship management skills", Industrial Marketing Management, Vol. 43 No. 7, pp.1110-1123.

*Gyau, A., Spiller, A. and Wocken, C. (2011), "Price or relational behaviours?”, British Food Journal, Vol. 113 No. 7, pp. 838-852.

*Han, S.-L. and Sung, H.-S. (2008), "Industrial brand value and relationship performance in business markets - A general structural equation model”, Industrial Marketing Management, Vol. 37 No. 7, pp. 807-818.

Hair Jr. J.F., Black, W.C., Babin, B.J. and Anderson, R.E., (2013), Multivariate data analysis, Pearson, New Jersey.

*Holmlund, M. (2008), “A definition, model, and empirical analysis of business-to-business relationship quality”, International Journal of Service Industry Management, Vol. 19 No. 1, pp. 32-62

*Jiang, Z., Henneberg, S.C. and Naudé, P. (2011), "Supplier relationship management in the construction industry. The effects of trust and dependence", Journal of Business \& Industrial Marketing, Vol. 27 No. 1, pp. 3-15.

Jiang, Z., Shiu, E., Henneberg, S. and Naudé, P. (2016), „Relationship quality in business to business relationships - Reviewing the current literatures and proposing a new measurement model", Psychology \& Marketing, Vol. 33 No. 4, pp. 297-313.

*Johnston, W.J., Khalil, S., Jain, M. and Cheng, J. M.-S. (2012), "Determinants of joint action in international channels of distribution: The moderating role of psychic distance", Journal of International Marketing, Vol. 20 No. 3, pp. 34-49.

*Kim, D., Basu, C., Naidu, G.M. and Cavusgil, E. (2011), "The innovativeness of Born-Globals and customer orientation: Learning from Indian Born-Globals”, Journal of Business Research, Vol. 64 No. 8, pp. 879-886. 
*Kühne, B., Gellynck, X. and Weaver, R.D. (2013), "The influence of relationship quality on the innovation capacity in traditional food chains", Supply Chain Management: An International Journal, Vol. 18 No. 1, pp. 52-65.

*Lahiri, S. and Kedia, B.L. (2011), "Determining quality of business-to-business relationships: A study of Indian IT-enabled service providers", European Management Journal, Vol. 29 No. 1, pp. 11-24.

*Lai, C.-S., Pai, D.-C., Yang, C.-F. and Lin, H.-J. (2009), "The effects of market orientation on relationship learning and relationship performance in industrial marketing: The dyadic perspectives", Industrial Marketing Management, Vol. 38 No. 2, pp. 166-172.

*Lai, F., Chu, Z., Wang, Q. and Fan, C. (2013), "Managing dependence in logistics outsourcing relationships. Evidence from China", International Journal of Production Research, Vol. 51 No. 10, pp. 3037-3054.

*Lee, E., Han, S., Nam, H.U. and Rho, J.J. (2013), "Building capabilities via suppliers' effective management of relationships", Industrial Marketing Management, Vol. 42 No. 5, pp. 805-813.

*Leonidou, C.N., Leonidou, L.C., Coudounaris, D.N. and Hultman, M. (2013), "Value differences as determinants of importers' perceptions of exporters' unethical behavior. The impact on relationship quality and performance", International Business Review, Vol. 22 No. 1, pp. 156-173.

*Leonidou, L.C., Palihawadana, D., Chari, S. and Leonidou, C.N. (2011), "Drivers and outcomes of importer adaptation in international buyer-seller relationships", Journal of World Business, Vol. 46 No. 4, pp. 527-543.

*Liu, Y., Li, Y. and Zhang, L. (2010), "Control mechanisms across a buyer-supplier relationship quality matrix”, Journal of Business Research, Vol. 63 No. 1, pp. 3-12.

*Lo, S.M. (2015), "Impact of greening attitude and buyer power on supplier environmental management strategy", International Journal of Environmental Science and Technology, Vol. 12 No. 10, pp. 31453160.

Mentzer, J.T., DeWitt, W., Keebler, J.S., Min, S., Nix, N.W., Smith, C.D. and Zacharia, Z.G. (2001), "Defining supply chain management", Journal of Business Logistics, Vol. 22 No. 2, pp. 1-25.

*Myhal, G.C., Kang, J. and Murphy, J.A. (2008), "Retaining customers through relationship quality. A services business marketing case”, Journal of Services Marketing, Vol. 22 No. 6, pp. 445-453.

*Mysen, T. and Svensson, G. (2010), "RELQUAL's impact on satisfaction in Norwegian business relationships", Journal of Business \& Industrial Marketing, Vol. 25 No. 2, pp. 119-131.

*Nyaga, G.N., Lynch, D.F., Marshall, D. and Ambrose, E. (2013), "Power asymmetry, adaptation and collaboration in dyadic relationships involving a powerful partner", Journal of Supply Chain Management, Vol. 49 No. 3, pp. 42-65.

*Nyaga, G.N. and Whipple, J.M. (2011), "Relationship quality and performance outcomes. Achieving a sustainable competitive advantage", Journal of Business Logistics, Vol. 32 No. 4, pp. 345-360.

Nyaga, G.N., Whipple, J.M., \& Lynch, D.F. (2010). Examining supply chain relationships: Do buyer and supplier perspectives on collaborative relationships differ? Journal of Operations Management, 28(2), 101-114.

*Obadia, C. and Vida, I. (2011), "Cross-border relationships and performance: Revisiting a complex linkage", Journal of Business Research, Vol. 64 No. 5, pp. 467-475.

*Palmatier, R.W. (2008), "Interfirm relational drivers of customer value", Journal of Marketing, Vol. 72 No. 4, pp. 76-89.

Palmatier, R.W., Dant, R.P., Grewal, D. and Evans, K.R. (2006), "Factors influencing the effectiveness of relationship marketing. A meta-analysis", Journal of Marketing, Vol. 70 No. 4, pp. 136-153.

*Payan, J.M., Svensson, G., Awuah, G., Andersson, S. and Hair, J. (2010), "A 'cross-cultural RELQUALscale' in supplier-distributor relationships of Sweden and the USA", International Marketing Review, Vol. 27 No. 5, pp. 541-561.

*Rauyruen, P. and Miller, K. E. (2007), "Relationship quality as a predictor of B2B customer loyalty", Journal of Business Research, Vol. 60 No. 1, pp. 21-31.

*Richard, J.E., Thirkell, P.C. and Huff, S.L. (2007), “An Examination of Customer Relationship Management (CRM) Technology Adoption and its Impact on Business-to-Business Customer Relationships", Total Quality Management \& Business Excellence, Vol. 18 No. 8, pp. 927-945.

*Sarmento, M., Simões, C. and Farhangmehr, M. (2015), "Applying a relationship marketing perspective to B2B trade fairs. The role of socialization episodes", Industrial Marketing Management, Vol. 44, pp. 131-141.

Sauer, P. C. and Seuring, S. (2017), "Sustainable supply chain management for minerals", Journal of Cleaner Production. Vol. 151, pp. 235-249.

Seuring, S. and Gold, S. (2012), "Conducting content-analysis based literature reviews in supply chain management”, Supply Chain Management: An International Journal, Vol. 17 No. 5, pp. 544-555. 
*Sheu, J.-B. (2015), "Power shifts and relationship quality improvement of producer-retailer green channel dyads under government intervention", Industrial Marketing Management, Vol. 50, pp. 97-116.

*Sjoerdsma, M. and van Weele, A.J. (2015), "Managing supplier relationships in a new product development context", Journal of Purchasing and Supply Management, Vol. 21 No. 3, pp. 192-203.

*Song, Y., Su, Q., Liu, Q. and Wang, T. (2012), "Impact of business relationship functions on relationship quality and buyer's performance”, Journal of Business \& Industrial Marketing, Vol. 27 No. 4, pp. 286298.

*Su, Q., Song, Y., Li, Z. and Dang, J. (2008), "The impact of supply chain relationship quality on cooperative strategy", Journal of Purchasing \& Supply Chain Management, Vol. 14 No. 4, pp. 263272.

*Svensson, G. and Mysen, T. (2011), “A construct of META-RELQUAL. Measurement model and theory testing”, Baltic Journal of Management, Vol. 6 No. 2, pp. 227-244.

*Tan, Y. C. and Ndubisi N. O. (2014), "Evaluating supply chain relationship quality, organizational resources, thecnological innovation and enterprise performance in the palm oil processing sector in Asia", Journal of Business \& Industrila Marketing, Vol. 29 No. 6, pp. 487-498.

Tranfield, D., Denyer, D. and Smart, P. (2003), "Towards a methodology for developing evidence-informed management knowledge by means of systematic review”, British Journal of Management, Vol. 14 No. 3, pp. 207-222.

*Ulaga, W. and Eggert, A. (2006), "Relationship value and relationship quality", European Journal of Marketing, Vol. 40 No. 3-4, pp. 311-327

*Wagner, S. M., Eggert, A. and Lindemann, E. (2010), "Creating and appropriating value in collaborative relationships", Journal of Business Research, Vol. 63 No. 8, pp. 840-848.

*Williams, P., Ashill, N.J., Naumann, E. and Jackson, E. (2015), "Relationship quality and satisfaction. Customer-perceived success factors for on-time projects", International Journal of Project Management, Vol. 33 No. 8, pp. 1836-1850.

*Wu, L.-Y., Chen, P.-Y. and Chen, K.-Y. (2015), "Why does loyalty-cooperation behavior vary over buyer-seller relationship?", Journal of Business Research, Vol. 68 No. 11, pp. 2322-2329.

*Wu, M., Weng, Y. and Huang, I. (2012), “A study of supply chain partnerships based on the commitmenttrust theory", Asia Pacific Journal of Marketing and Logistics, Vol. 24 No. 4, pp. 690-707.

*Zaefarian, G., Henneberg, S.C. and Naudé, P. (2011), "Resource acquisition strategies in business relationships", Industrial Marketing Management, Vol. 40 No. 6, pp. 862-874.

*Zander, K. and Beske, P. (2014), "Happy Growers! Relationship quality in the german organic apple chain”, International Food and Agribusiness Management Review, Vol. 17 No. 3, pp. 205-224.

*: Paper contained in the literature review. 